\title{
Bortezomib-Induced Cardiac Dysfunction in a Patient with Plasma Cell Leukemia-A Remote Complication
}

\author{
Zunaira Rafiq, Mehwesh Taj and Tahir Shamsi*
}

Department of Clinical Haematology and Bone Marrow Transplantation National Institute of Blood Diseases and Bone Marrow Transplantation ST 2/A, Block-17, Gulshan-e-Iqbal, Karachi, Pakistan.

\begin{abstract}
Bortezomib is an important proteasome inhibitor widely used in plasma cell neoplasms. An acute cardiac dysfunction is not a frequent side effect of bortezomib, but it is mentioned in literature search via multiple case reports. We have discussed here, another case of a young male diagnosed with plasma cell leukemia on treatment, presenting with sudden onset dyspnea due to an acute myocardial toxicity which subsequently upon thorough evaluation turned out to be an association with cyclical bortezomib administration.
\end{abstract}

Keywords: Bortezomib-induced, cardiac dysfunction, plasma cell leukemia. doi.org/10.21089/njhs.11.0041

\section{INTRODUCTION}

Bortezomib $\left(\right.$ Velcade $\left.^{\circledR}\right)$ is linked with cardiac dysfunction in multiple case reports but no association is determined by any clinical study up till now. It is FDA approved as a first choice drug for multiple myeloma and in patients with mantle cell lymphoma who should have received at least one prior therapy. Bortezomib is known to reversibly block the proteosomal activity in cancer cells and as well as normal body cells including cardiac myocytes. Most cases of heart failure secondary to inherited cardiomyopathies exhibit accumulation of ubiquitinated proteins, abnormal protein aggregation such as pre-amyloid oligomers, and altered proteasomal activities [1]. An exact mechanism of bortezomib-induced cardiac dysfunction and a reason for cardiac myocytes vulnerability for this acquired, drug induced proteasome inhibition is still unexplored.

Here we present a case of plasma cell leukaemia that developed sudden onset systolic left ventricle dysfunction after treatment with bortezomib.

\section{CASE REPORT}

A 44-year-old male, known to have hypothyroidism since last 6 years with no other comorbidity and risks for cardiac illness, presented to the outpatient service. He had a history of high-grade febrile episodes associated with a sore throat and mild non-productive cough for one week and

*Address correspondence to this author at the Haematology and Internal Medicine, Stem Cell Research and Regenerative Medicine, Haematologist and Transplant Physician, HEC Approved PhD Supervisor, National Institute of Blood Diseases and Bone Marrow Transplantation, Karachi, Pakistan, Email: tahir.shamsi@nibd.edu.pk unintentional weight reduction of 4 kilograms in one month. His CBC done a week earlier showed abnormal circulating lympho-cytes. His past medical and surgical history were unremarkable. There was no history of any blood transfusions. He has been on levothyroxine $100 \mathrm{mcg}$ per day. At this dose, he was maintaining normal TSH status. He was a non-smoker and never indulged in any substance abuse. There had not been any travel abroad in the preceding year. His mother was diabetic. Review of systems did not reveal anything beside weight loss. His general physical and systemic examination was absolutely fine with no finding in any system at all.

His initial tests done at the time of presentation to us, $\mathrm{Hb}$ $10.2 \mathrm{~g} / \mathrm{dl}$, TLC $97 \times 10^{9} / \mathrm{dl}$, ANC $0.3 \times 10^{9} / 1$, ALC $78 \times 10^{9} / 1$ and Platelets $49 \times 10^{9} /$. His flowcytometric analysis on peripheral blood yielded $79.5 \times 10^{9}(80 \%)$ circulating plasma cells confirming the diagnosis of plasma cell leukemia. His bone marrow analysis showed infiltration by plasmacytoid cells. There was no monoclonal band on serum protein electrophoresis. FISH analysis for del $17 \mathrm{p}$ was negative. Renal and liver functions were normal at baseline.

He received a combination of bortezumib, leno ledamide, dexamethasone and cyclophosphamide for this treatment [24]. The total dose of bortezomib was $19.2 \mathrm{mg} / \mathrm{m}^{2}$ and the cumulative dose of cyclophosphamide $2.4 \mathrm{~g} / \mathrm{m}^{2}$ over 24 weeks was given. Adjuvant antimicrobial prophylaxis against fungal, viral and Pneumocystis jiroveci pneumonia was also given. He achieved hematological remission 6 months since his treatment despite being started. There was $0.03 \%$ corresponding with $10-4$ abnormal plasma cells on immunophenotyping. Due to his MRD positive status, his 
autologous HSCT was planned immediately after a month of his last post chemotherapy outpatient follow-up.

A month later, he presented with complains of lethargy, nonproductive cough and pain in left leg. He was treated symptomatically, reassured and counseled for the transplant. Five days later, he was brought to emergency room with severe shortness of breath, orthopnea, paroxysmal nocturnal dyspnea and a very disturbing constant dry cough since last 3 days. There was no fever, sore throat or chest pain. All his symptoms developed after physical rehabilitation exercises he sought for his leg pain 3 days back. He denied for receiving any vaccination or a new drug intake recently. Upon evaluation, he was alert, oriented and conscious. He appeared puffy, was pale \& distressed, barely able to complete a full sentence in one breath. His blood pressure was 90/40, pulse 62/min (low volume and irregular), respiratory rate $48 / \mathrm{min}$ and temperature of $98^{\circ} \mathrm{F}$. Oxygen saturation was $87 \%$ on room air. His JVP was raised and bilateral pedal edema was present. His lungs were full of fine crackles in all areas upon auscultation with no wheezes or pleural rub. On cardiac examination, he had displaced apex beat, no palpable thrill or left parasternal heave. Upon auscultation, heart sounds were audible with variable interval and intensity and gallop rhythm was heard. No murmur or pericardial rub was appreciated.
His abdominal examination showed clear oral cavity, distended abdomen, tender right hypochondrium \& no visceral enlargement. Shifting dullness was present. Gut sounds were audible. Neurological examination was unremarkable.

His laboratory workup was done. Supplemental O2 via facemask, aspirin and clopidogrel PO and IV furosemide administered. He was then referred to cardiology experts after this short emergency management.

In the work up, his electrocardiogram showed no ST-T changes suggestive of an underlying ischemia, but various tachyarrhythmias were seen on constant monitoring. He was having episodes of self-remitting atrial fibrillation, Averts and Premature atrial contractions with sinus tachycardia.

His Transthoracic Echocardiography displayed severe global hypokinetic left ventricle, severely dilated left atrium and left ventricle, severe left ventricle systolic dysfunction, severe mitral regurgitation and tricuspid regurgitation, moderate pulmonary arterial hypertension and minimally reduced systolic right ventricle dysfunction. His ejection fraction was 20-25\%. Chest X-ray showed occasional soft shadows in middle and lower medial zones with normal cardiothoracic ratio.

The lab test results are shown in (Table 1).

Table 1. Investigations.

\begin{tabular}{|c|c|c|c|c|c|c|c|}
\hline Test & Value & Test & Value & Test & Value & Test & Value \\
\hline Troponin I & $\begin{array}{l}\text { Negative on qualitative assay at } 0 \\
\text { hr } 0.016 \mathrm{ng} / \mathrm{ml} \text { after } 24 \text { hours }\end{array}$ & Chloride & $94 \mathrm{mg} / \mathrm{dl}$ & CRP & $>120 \mathrm{mg} / \mathrm{dl}$ & $\mathrm{T} 3$ & $0.78 \mathrm{pmol} / \mathrm{L}$ \\
\hline Troponin $\mathrm{T}$ & Negativeon qualitative assay at $0 \mathrm{hr}$ & bicarbonte & $18 \mathrm{mg} / \mathrm{dl}$ & $\mathrm{Hb}$ & $9.8 \mathrm{~g} / \mathrm{dl}$ & $\mathrm{T} 4$ & $5.68 \mathrm{pmol} / \mathrm{L}$ \\
\hline Pro BNP & $994.4 \mathrm{ng} / \mathrm{L}$ & Total Bilirubin & $1.0 \mathrm{mg} / \mathrm{dl}$ & TLC & $8.6 \times 10^{9} / \mathrm{L}$ & $\begin{array}{c}\text { Total } \\
\text { cholesterol }\end{array}$ & $116 \mathrm{nmol} / \mathrm{L}$ \\
\hline Urea & $28 \mathrm{mg} / \mathrm{dl}$ & Direct Bilirubin & $0.6 \mathrm{mg} / \mathrm{dl}$ & ANC & $6.19 \times 10^{9} / \mathrm{L}$ & VLDL & $54 \mathrm{mg} / \mathrm{dl}$ \\
\hline Creatinine & $0.7 \mathrm{mg} / \mathrm{dl}$ & ALP & $87 \mathrm{U} / \mathrm{L}$ & ALC & $1.63 \times 10^{9} / \mathrm{L}$ & LDL & $48 \mathrm{mg} / \mathrm{dl}$ \\
\hline $\mathrm{Na}$ & $129 \mathrm{mg} / \mathrm{dl}$ & ALT & $1518 \mathrm{U} / \mathrm{L}$ & Platelets & $107 \times 10^{9} / \mathrm{L}$ & HDL & $20 \mathrm{mg} / \mathrm{dl}$ \\
\hline
\end{tabular}

On the basis of the absent ST-T changes on ECG, negative cardiac biomarkers, and global hypokinesia on echocardiography which are not a feature of acute myocardial infarction, dilated cardiomyopathy was suspected as a case of an acute heart failure.

\section{DIFFERENTIAL DIAGNOSIS}

Normal thyroid profile essentially excludes occult thyrotoxicosis or myxedema as a reason for an underlying heart failure while an absence of ST segment and T wave changes and negative troponin results raises the suspicion of an acute myocarditis. An absence of fever, upper respiratory illness, high white cell count, pleuritic or pericardial chest pain and recent vaccination excludes a viral myocarditis. Due to an absence of any associated factors for a dilated cardiomyopathy besides drug toxicity and echocardiographic findings exhibiting gross systolic dysfunction and aberrant myocardial expansion, an underlying drug-related cardio- 
myopathy is strongly suggestive as a cause of sudden heart failure in our patient.

\section{FINAL CLINICAL DIAGNOSIS}

Since cyclophophamide in cyclical low doses (less than 1.5 $\mathrm{g} / \mathrm{m}^{2}$ ) is not associated with systolic LV dysfunction through clinical studies [2-4], the most likely diagnosis in our case was Bortezomib induced LV systolic dysfunction.

\section{POST EVENT FOLLOW-UP}

His systolic dysfunction persisted after a follow-up echocardiogram after one year with an improvement in ejection fraction I.e. $30-35 \%$. He is ambulatory and able to perform the routine daily activity. He has rejoined his office job recently and has been started on lenalidomide, melphalan and dexamethasone as his maintenance chemotherapy. He is still enjoying remission and his underlying cardiac function has greatly improved now.

\section{DISCUSSION}

Bortezomib is associated with systolic LV dysfunction in many case reports in literature. The incidence of cardiac dysfunction described in a Journal of American College Cardiology 2009 is 1-5\% [5]. Bortezomib is dipeptide boronic acid that acts as a proteasome inhibitor inside the cells. It impairs the activation of NF-KB, which is important for cell survival. Through NF-KB inhibition bortezomib inhibits bcl-2 phosphorylation and breakdown, causing G2$\mathrm{M}$ phase cell cycle arrest, hence cellular apotosis [6, 7]. A growing body of evidence indicates impairment of the ubiqitin proteosome system in inherited cardiomyopathies as determined by measurement of the level of ubiquitinated proteins, the activities of the proteasome and/or the use of fluorescent UPS reporter substrates [1]. A similar mechanism might propose an acquired cardiomyopathy induced by cellular inhibition of proteomes via bortezomib. Whether this is an underlying cause or not a thorough search warrants further exploration into the exact mechanism of cardiac dysfunction induced by bortezomib. A study on rats so far has produced left ventricular contractile dysfunction manifested by a significant drop in left ventricle ejection fraction when they were subjected to bortezomib administration [6]. A literature search done for the various reported cases 7-14 of systolic heart dysfunction induced by bortezomib shows the average threshold level of cardiac dysfunction happening to be around total dose beyond 20 $\mathrm{mg} / \mathrm{m} 2$ in individuals with de novo heart failure. In postevent follow-ups mentioned in those case studies there is an evidence of improvement in the cardiac function after bortezomib discontinuation.

There is no established consensus at present to recommend the preemptive measures to be taken before initiation of bortezomib, for detection of an underlying asymptomatic cardiac dysfunction [5]. It is logical to get an echocardio- gram done if there are associated cardiac risk factors (smoking, diabetes, hypertension and hyperlipidemia) or history of an underlying cardiac disease and patients should be counseled for the possibility of this important adverse effect before suggesting bortezomib cycles for their underlying malignant disorder. There also should be a further study in the role of cardiac MRI, radio-nuclear scanning, cardiac biopsy or other sophisticated diagnostic tools in these cancer patients, in order to reach an exact pathologic diagnosis in this sudden post chemotherapyinduced systolic LV dysfunction.

\section{CONCLUSION}

Bortezomib has an adverse side effect of LV systolic dysfunction that should be born in mind when dealing with any individual receiving it. A slight hint of chronic fatigue or shortness of breath on exertion observed in any patient before, during or after receiving bortezomib should be taken into an account, and a thorough evaluation is recommended.

\section{ACKNOWLEDGEMENT}

Declared none.

\section{CONFLICT OF INETERST}

Declared none.

\section{REFERENCES}

[1] Schlossarek S, Frey N, Carrie L. Ubiquitin-proteasome system and hereditary cardiomyopathies. J. Mol. Cell Cardiol., 2014; 71: 25.

[2] Gottdiener JS. Cardiotoxicity associated with high-dose cyclophosphamide therapy. Arch. Intern. Med., 1981; 141:758.

[3] Slavin RE, Millan JC, Mullins GM. Pathology of high dose intermittent cyclophosphamide therapy. Hum. Pathol., 1975; 6: 693.

[4] Gharib MI, Burnett AK. Chemotherapy-induced cardiotoxicity: current practice and prospects of prophylaxis. Europ. J. Heart Failure, 2002; 4: 235.

[5] Yeh ETH, Bickford CL. Cardiovascular Complications of Cancer Therapy Incidence, Pathogenesis, Diagnosis, and Management. J. Am. Coll. Cardiol., 2009; 53: 2231

[6] Nowis D. Cardiotoxicity of the anticancer therapeutic agent bortezomib. Am. J. Pathol., 2010; 176: 2658.

[7] Yang F. Bortezomib induces apoptosis and growth suppression in human medulloblastoma cells, associated with inhibition of AKT and NF-KB signaling, and synergizes with an ERK inhibitor. Cancer Biol. Ther., 2012; 13:349.

[8] Gupta A, Pandey A, Sethi S. Bortezomib-Induced Congestive Cardiac Failure in a Patient with Multiple Myeloma. Card. Vasc. Tox., 2012; 12: 184.

[9] Manickam P, Shenoy M, Woldie I, Hari P, Tuliani T, Byrnes T. Bortezomib-induced Dilated cardiomyopathy - Myth or Reality. EJ. Cardiol., 2011; 1:40.

[10] Chakraborty R, Kumar S, Mukkamalla R, Calderon N. Bortezomib induced reversible left ventricular systolic dysfunction: A case report and review of literature. BJMP 2013; 6: 631.

[11] Voortman J, Giaccone G. Severe reversible cardiac failure after bortezomib treatment combined with chemotherapy in a non-small cell lung cancer patient: a case report. BMC Cancer, 2006; 6: 129. 
[12] Hacihanefioglu A, Tarkun P, Gonullu E. Acute severe cardiac failure in a myeloma patient due to proteasome inhibitor bortezomib, Int. J. Hematol., 2008; 88: 219.

[13] Orciuolo E, Buda G, Cecconi N. Unexpected cardiotoxicity in haematological bortezomib treated patients, 2007; 138: 396.
[14] Jerkins JH, Suciu A, Mazimba S, Calvo A. Bortezomib induced Severe Congestive Heart Failure. Cardiol. Res., 2010; 1: 20.

Copyright $\odot 2016$ NJHS - All Rights Reserved

This is an open-access article. 